\title{
Knowledge and Attitude towards Cervical Cancer and Human Papillomavirus among Pharmacists in Japan
}

\author{
Ai Sasaki", Yuki Nakao', Taku Obara ${ }^{2,3,4 *}$, Shinya $\mathrm{Abe}^{5}$, Hiroshi Yamaguchi, \\ Shoko Yoshimachi ${ }^{5}$, Teruaki Goto ${ }^{5}$
}

\begin{abstract}
Objective: The objective of this study was to assess the knowledge and attitude towards cervical cancer and human papillomavirus (HPV) among pharmacists in Japan. Methods: Questionnaires were disseminated to 788 pharmacists employed by the Tsuruha Holdings Inc. A total of 617 pharmacists responded, generating a response rate of $78.3 \%$. Result: Of the 362 females and 255 males, vaccination rates were $14.4 \%$ and $0.8 \%$, respectively. In terms of cervical cytology, $35.1 \%$ of females received it once every two years, and $26.2 \%$ received it irregularly. As for HPV testing, $12.2 \%$ of females received it once every two years, and $16.6 \%$ received it irregularly. The rate of "school curriculum" as an information source was significantly higher among younger pharmacists; while "internet", "media", "training seminar for pharmacist", "advertisement in medical institution", "internal manual", and "others" were significantly higher among older pharmacists. The proportion of pharmacists with knowledge on general questions, except for those about HPV testing, was significantly higher among females than males. The vaccination rates of younger pharmacists were significantly higher than those of older pharmacists. The screening rates of cervical cytology were significantly higher among older than younger pharmacists, and also among those with at least 10 years of experience than those with less. There were no differences in the screening rates of HPV testing according to age or pharmacist experience. Conclusion: The proportion of pharmacists with knowledge about cervical cancer and HPV significantly varied depending on sex, age, and experience as a pharmacist. This study suggested that spreading the knowledge about cervical cancer and HPV might be effective for increasing the rates of cervical cancer screening.
\end{abstract}

Keywords: cervical cancer- human papillomavirus- Japan- pharmacists- papillomavirus vaccines

Asian Pac J Cancer Prev, 22 (7), 2259-2265

\section{Introduction}

Cervical cancer is one of the most common cancers of the female genital system globally. In 2018, approximately 570,000 women were diagnosed with cervical cancer, and 311,000 died from it (GLOBOCAN, 2019). Cervical cancer is caused by sexually acquired infections with certain types of human papillomavirus (HPV), particularly, HPV types 16 and 18 which cause $70 \%$ of cervical cancers and precancerous cervical lesions (WHO, 2020). Comprehensive cervical cancer control includes HPV vaccination as primary prevention, screening and treatment of pre-cancerous lesions as secondary prevention, diagnosis and treatment of invasive cervical cancer tertiary prevention as tertiary prevention and palliative care (WHO, 2020). The significance of primary and secondary prevention of HPV-related diseases has become a worldwide concern. In 2018, the International
Papillomavirus Society stated that in order to eliminate cervical cancer as a public health problem, high coverage HPV vaccination for adolescents and high coverage cervical cancer screening, should be done in combination with appropriate treatment for all women (Garland et al., 2018).

In April 2013, the Japanese Ministry of Health, Labour and Welfare (MHLW) implemented the national HPV vaccine program which provided free immunization for girls aged 12-16 years (Simms et al., 2020). However, in June 2013, the program was suspended after unconfirmed reports of adverse events following vaccination appeared in the media (Gilmour et al., 2013). Since then, completion rates of the three-dose HPV series fell to less than $1 \%$ in 2013 from $68.4-74.0 \%$ in $2007-2011$ (Hanley et al., 2015), despite the vaccine still being part of the national immunization program and available for free. Japan has since become a country with strong HPV vaccine

${ }^{1}$ Tsuruha Pharmacies Co., Ltd. Sapporo, Hokkaido, Japan. ${ }^{2}$ Division of Preventive Medicine and Epidemiology, Tohoku University Tohoku Medical Megabank Organization, Sendai, Miyagi, Japan. ${ }^{3}$ Department of Molecular and Epidemiology, Tohoku University Graduate School of Medicine, Sendai, Miyagi, Japan. ${ }^{4}$ Department of Pharmaceutical Sciences, Tohoku University Hospital, Sendai, Miyagi, Japan. ${ }^{5}$ Tsuruha Holdings Inc, Sapporo, Hokkaido, Japan. *For Correspondence: obara-t@hosp.tohoku.ac.jp 
hesitancy due to widespread public suspicion of adverse events. As for cervical cancer screening in Japan, the uptake rates within two years approximated at $42.4 \%$ (Japanese MHLW, 2016), this reflected the failure of reaching the government target of $50 \%$, even though screening is provided at a subsidized price. Prevention strategies in Japan are insufficient as compared with other countries which achieve high vaccination and screening coverage such as Australia (Hall et al., 2019) and many other desirable countries (Bruni et al., 2016; Gakidou et al., 2008; OECD, 2013).

WHO reported that community pharmacists are the most accessible health professionals to the public and are cornerstones of primary health care (WHO, 2019). Community pharmacists play a key role in health promotion campaigns, locally and nationally, on a wide range of health-related topics. In 2016, the Japanese MHLW introduced the Health Support Pharmacy (HSP) system to promote awareness of public health through community pharmacy services, including dementia support, nutritional guidance, and health consultation, among others. However, it was reported that service quality differed across pharmacies, and adequate resources and professional expertise are required to improve the quality of pharmacy-based public health services (Sato et al., 2020). Pharmacists have a role in spreading appropriate knowledge and in encouraging preventive behavior of cervical cancer. Although several investigations have clarified the state of knowledge and attitude towards HPV and cervical cancer among the general population in Japan (Miyagi et al., 2014; Sukegawa et al., 2015; Suzuki et al., 2019), the knowledge and attitude among pharmacists and the relationship between them are unknown. The objective of this study was therefore to assess the knowledge and attitude towards cervical cancer and HPV and the relationship between them among pharmacists in Japan.

\section{Materials and Methods}

Pharmacists employed by the Tsuruha Holdings Inc., a Japanese drugstore chain, were surveyed. A selfadministered questionnaire was used to assess their knowledge about cervical cancer, HPV, and cervical cancer screening, as well as their experiences of HPV vaccination and cervical cancer screening (Suppl 1). Tsuruha Holdings Inc. headquarters disseminated these questionnaires to 788 pharmacists, who were asked to submit them through a web system between June 4-24, 2019. A total of 617 pharmacists responded, giving a response rate of $78.3 \%$. The results were analyzed by stratification according to sex, age ( $<30$ years, 30-39 years, 40-49 years, and $\geq 50$ years), and experience as a pharmacist ( $<10$ years and $\geq 10$ years). The participants who responded "I understand" to the question regarding their understanding of cervical cancer and HPV were classified into the "Yes" group, while those who answered "I have heard, but don't understand" or "I don't know" were classified into the "No" group. Participants in the "Yes" group were considered to have knowledge about the topic of each question on cervical cancer and HPV. "HPV testing" means HPV testing alone, not including co- testing with cervical cytology. We compared the sources of information according to age. We also compared the attitude towards HPV vaccination and cervical cancer screening including cervical cytology and HPV testing in the same manner. Statistical analyses were performed by the Fisher's exact probability test and the CochranArmitage trend test using the SAS package (version 9.4; SAS Institute Inc., Cary, NC, USA).

\section{Results}

Of the 617 pharmacists, $58.8 \%$ were female, $70.5 \%$ were $<40$ years, and $55.7 \%$ had $<10$ years of pharmacist experience. Of the 362 females and 255 males, vaccination rates were $14.4 \%$ and $0.8 \%$, respectively. In terms of cervical cytology, $35.1 \%$ of females received it once every two years, and $26.2 \%$ received it irregularly. As for HPV testing, $12.2 \%$ of females received it once every two years, and $16.6 \%$ received it irregularly.

\section{Source of information on cervical cancer according to age}

The source of information on cervical cancer were different across age groups (Figure 1). The rate of "school curriculum" as an information source was significantly higher among younger pharmacists; while "internet", "media", "training seminar for pharmacist", "advertisement in medical institution", "internal manual", and "others" were significantly higher among older pharmacists.

\section{Knowledge related to cervical cancer and HPV}

The proportion of pharmacists with knowledge on general questions, except for those about HPV testing, was significantly higher among females than males (Table 1). Between the age groups, knowledge about the relationship between HPV and cervical cancer, the transmission route of HPV, and HPV testing were significantly higher among younger pharmacists; while knowledge about cervical cytology and the subsidization of cervical cancer screening were significantly higher among older pharmacists. In terms of pharmacist experience, knowledge about the relationship between HPV and cervical cancer, the transmission route of HPV, and the HPV testing were significantly higher among those who had worked as a pharmacist for less than 10 years, while knowledge about cervical cytology and the subsidization of cervical cancer screening were significantly higher among pharmacists with at least 10 years of experience.

\section{Attitude towards HPV vaccination according to characteristics among female pharmacists}

The vaccination rates of younger pharmacists were significantly higher than those of older pharmacists (Table 2 ). Vaccination rates were also significantly higher in pharmacists with less than 10 years of experience than those with at least 10 years. The proportions of female pharmacists who have received HPV vaccines were significantly higher among those with knowledge about the transmission route of HPV and HPV vaccines, as compared to those without such knowledge. 
DOI:10.31557/APJCP.2021.22.7.2259

Pharmacists' Knowledge and Attitude about HPV

Table 1. Knowledge Related to Cervical Cancer and HPV

\begin{tabular}{|c|c|c|c|c|c|c|c|c|c|c|c|}
\hline & \multicolumn{3}{|c|}{ Sex } & \multicolumn{5}{|c|}{ Age } & \multicolumn{3}{|c|}{ Experience as pharmacist } \\
\hline & $\begin{array}{c}\text { Female } \\
n=362\end{array}$ & $\begin{array}{c}\text { Male } \\
\mathrm{n}=254\end{array}$ & $\mathrm{P}^{*}$ & $\begin{array}{c}<30 \text { years } \\
n=223\end{array}$ & $\begin{array}{c}30-39 \text { years } \\
n=211\end{array}$ & $\begin{array}{c}40-49 \text { years } \\
n=81\end{array}$ & $\begin{array}{c}\geq 50 \text { years } \\
n=101\end{array}$ & $\mathrm{P} * *$ & $\begin{array}{c}<10 \text { years } \\
n=343\end{array}$ & $\begin{array}{c}\geq 10 \text { years } \\
n=273\end{array}$ & $\mathrm{P}^{*}$ \\
\hline \multicolumn{12}{|c|}{ Do you know about cervical cancer which develops in uterine cervix? } \\
\hline Yes, $\%$ & 71.3 & 60.6 & 0.006 & 66.4 & 63.5 & 64.2 & 77.2 & 0.111 & 65.3 & 68.9 & 0.389 \\
\hline \multicolumn{12}{|c|}{ Do you know about HPV with which most people experience infection? } \\
\hline Yes, \% & 68.8 & 50.4 & $<0.0001$ & 65.9 & 57.8 & 56.8 & 61.4 & 0.288 & 62.4 & 59.7 & 0.507 \\
\hline \multicolumn{12}{|c|}{ Do you know that persistent infection with HPV can lead to cervical cancer? } \\
\hline Yes, \% & 77.4 & 69.7 & 0.032 & 82.5 & 70.6 & 71.6 & 65.4 & 0.001 & 79.3 & 67.8 & 0.002 \\
\hline \multicolumn{12}{|c|}{ Do you know that HPV can be transmitted by sexual intercourse? } \\
\hline Yes, \% & 84.3 & 77.2 & 0.026 & 90.1 & 78.7 & 75.3 & 72.3 & $<0.0001$ & 86.0 & 75.5 & 0.001 \\
\hline \multicolumn{12}{|c|}{ Do you know about HPV vaccines? } \\
\hline Yes, \% & 69.9 & 54.3 & $<0.0001$ & 72.7 & 54.5 & 58.0 & 66.3 & 0.135 & 66.8 & 59.3 & 0.064 \\
\hline \multicolumn{12}{|c|}{ Do you know about HPV testing? } \\
\hline Yes, $\%$ & 11.1 & 24.8 & $<0.0001$ & 22.0 & 15.6 & 12.4 & 10.9 & 0.006 & 20.4 & 12.1 & 0.007 \\
\hline \multicolumn{12}{|c|}{ Do you know about cervical cytology? } \\
\hline Yes, \% & 35.4 & 19.3 & $<0.0001$ & 21.1 & 31.8 & 33.3 & 35.6 & 0.004 & 23.0 & 35.9 & 0.001 \\
\hline \multicolumn{12}{|c|}{ Do you know differences of the cervical cytology and the HPV testing? } \\
\hline Yes, \% & 30.4 & 18.5 & 0.001 & 26.0 & 20.9 & 19.8 & 38.6 & 0.073 & 24.5 & 26.7 & 0.577 \\
\hline \multicolumn{12}{|c|}{ Do you know that you can receive cervical cancer tests at a subsidized price by companies or governments? } \\
\hline Yes, \% & 69.6 & 34.7 & $<0.0001$ & 50.2 & 55.5 & 59.3 & 62.4 & 0.028 & 51.3 & 60.1 & 0.034 \\
\hline
\end{tabular}

HPV, human papillomavirus; *, Fisher's exact test; **, Cochran-Armitage trend test.

Attitude towards cervical cytology among female pharmacists

The proportion of female pharmacists who received cervical cytology, be it once every two years or irregularly, were significantly higher among older than younger pharmacists, and also among those with at least 10 years of experience than those with less (Table 3). Rate of cervical cytology was also significantly higher among pharmacists with knowledge about cervical cancer, HPV, cervical cytology, the differences between cervical cytology and HPV testing, and the subsidization of cervical cancer screening, compared to those without such knowledge. Lastly, cervical cytology rate was significantly higher among pharmacists without knowledge about HPV testing,

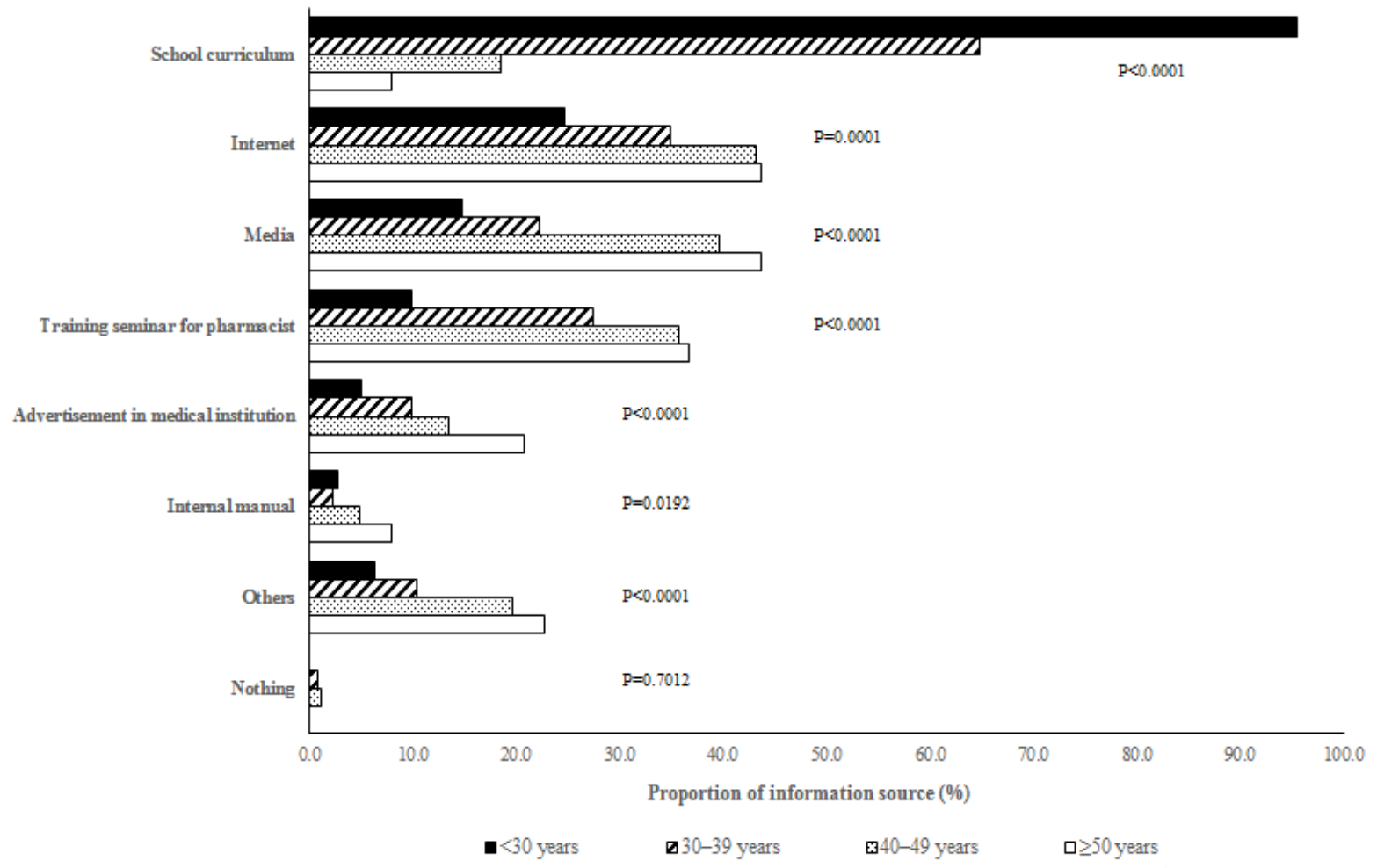

Figure 1. Source of Information on Cervical Cancer According to Age. P-values were expressed the results from the Cochran-Armitage trend test among age groups. 
Table 2. Attitude towards HPV Vaccination among Female Pharmacists

\begin{tabular}{lcc}
\hline & $\begin{array}{c}\text { HPV vaccination } \\
\text { rate, } \%\end{array}$ & $\mathrm{P}^{*}$ \\
\hline Age & 29.2 & $<0.0001^{* *}$ \\
$<30$ years & 9.5 & \\
$30-39$ years & 3.8 & \\
40-49 years & 0.0 & \\
$\geq 50$ years & & \\
Experience as pharmacist & 22.4 & $<0.0001$ \\
$<10$ years & 4.4 & \\
$\geq 10$ years & &
\end{tabular}

Do you know about cervical cancer which develops in uterine cervix?

$\begin{array}{lll}\text { No } & 19.2 & 0.100 \\ \text { Yes } & 12.4 & \end{array}$

Do you know about HPV with which most people experience infection?

$\begin{array}{lll}\text { No } & 14.2 & 1.000 \\ \text { Yes } & 14.5 & \end{array}$

Do you know that persistent infection with HPV can lead to cervical cancer?

$\begin{array}{lcc}\text { No } & 9.8 & 0.212 \\ \text { Yes } & 15.7 & \end{array}$

Do you know that HPV can be transmitted by sexual intercourse?

$\begin{array}{lcc}\text { No } & 5.3 & 0.038 \\ \text { Yes } & 16.1 & \end{array}$

Do you know about HPV vaccines?

$\begin{array}{lcc}\text { No } & 7.3 & 0.014 \\ \text { Yes } & 17.4 & \\ \text { Do you know about cervical cytology? } & & \\ \text { No } & 13.0 & 0.054 \\ \text { Yes } & 25.0 & \\ \text { Do you know about HPV testing? } & & \\ \text { No } & 15.0 & 0.755 \\ \text { Yes } & 13.3 & \end{array}$

Do you know differences of the cervical cytology and the HPV testing?

$$
\begin{array}{lll}
\text { No } & 15.9 & 0.256 \\
\text { Yes } & 10.9 &
\end{array}
$$

Do you know that you can receive cervical cancer tests at a subsidized price by companies or governments?

$\begin{array}{lll}\text { No } & 19.1 & 0.104 \\ \text { Yes } & 12.3 & \end{array}$

HPV, human papillomavirus; *, Fisher's exact test; **, CochranArmitage trend test.

compared to those with this knowledge.

Attitude towards HPV testing among female pharmacists

There were no differences in the screening rates of HPV testing (once every 2 years or irregularly) according to age or pharmacist experience (Table 4). HPV testing rate was significantly higher among pharmacists with knowledge about cervical cancer, HPV, the relationship between HPV and cervical cancer, HPV vaccines, HPV testing, the differences between cervical cytology and HPV testing, and the subsidization of cervical cancer
Table 3. Attitude towards Cervical Cytology among Female Pharmacists

\begin{tabular}{lcccc}
\hline & $\begin{array}{c}\text { Once } \\
\text { every two } \\
\text { years, } \%\end{array}$ & P* & $\begin{array}{c}\text { "Once every } \\
\text { two years or } \\
\text { irregular, \%" }\end{array}$ & \\
\hline Age & & & & \\
$<30$ years & 21.2 & $<.0001^{* *}$ & 42.3 & $<0.0001^{* *}$ \\
30-39 years & 34.3 & & 70.5 & \\
40-49 years & 49.1 & & 79.3 & \\
$\geq 50$ years & 53.7 & & 71.6 & \\
Experience as pharmacist & & & \\
$<10$ years & 23.4 & $<0.0001$ & 48.3 & $<0.0001$ \\
$\geq 10$ years & 49.7 & & 77.6 &
\end{tabular}

Do you know about cervical cancer which develops in uterine cervix?

$\begin{array}{lllll}\text { No } & 21.2 & 0.0004 & 45.2 & <0.0001 \\ \text { Yes } & 40.7 & & 67.8 & \end{array}$

Do you know about HPV with which most people experience infection?

$\begin{array}{lllll}\text { No } & 25.7 & 0.013 & 51.3 & 0.010 \\ \text { Yes } & 39.4 & & 65.9 & \end{array}$

Do you know that persistent infection with HPV can lead to cervical cancer?

$\begin{array}{lllll}\text { No } & 29.3 & 0.237 & 53.7 & 0.122 \\ \text { Yes } & 36.8 & & 63.6 & \end{array}$

Do you know that HPV can be transmitted by sexual intercourse?

$\begin{array}{lllll}\text { No } & 26.3 & 0.173 & 57.9 & 0.558 \\ \text { Yes } & 36.7 & & 62.0 & \end{array}$

Do you know about HPV vaccines?

$\begin{array}{lllll}\text { No } & 27.5 & 0.055 & 61.5 & 1.000 \\ \text { Yes } & 38.3 & & 61.3 & \end{array}$

Do you know about HPV testing?

$\begin{array}{lcccc}\text { No } & 38.5 & 0.0001 & 65.8 & <0.0001 \\ \text { Yes } & 7.5 & & 25.0 & \end{array}$

Do you know about cervical cytology?

$\begin{array}{lllll}\text { No } & 31.2 & 0.036 & 53.4 & <0.0001 \\ \text { Yes } & 42.2 & & 75.8 & \end{array}$

Do you know differences of the cervical cytology and the HPV testing?

$\begin{array}{lllll}\text { No } & 30.2 & 0.004 & 57.9 & 0.047 \\ \text { Yes } & 46.4 & & 69.1 & \end{array}$

Do you know that you can receive cervical cancer tests at a subsidized price by companies or governments?

\begin{tabular}{lllll} 
No & 15.5 & $<0.0001$ & 42.7 & $<0.0001$ \\
Yes & 43.7 & & 69.4 & \\
\hline
\end{tabular}

HPV, human papillomavirus; *, Fisher's exact test; **, CochranArmitage trend test.

screening, compared to those without such knowledge. HPV testing rate was also significantly higher among the pharmacists without knowledge about cervical cytology, compared to those with this knowledge.

\section{Discussion}

Many reports have revealed a positive correlation between knowledge and vaccination coverage (Oz et al., 2018; Navalpakam et al., 2019; Liu et al., 2020); however, few reports have examined the correlation between knowledge and screening coverage. Worldwide simulations have shown that the proper combination of 
Table 4. Attitude towards HPV Testing among Female Pharmacists

\begin{tabular}{lcccc}
\hline & $\begin{array}{c}\text { Once every } \\
\text { two years, } \\
\%\end{array}$ & $\mathrm{P}^{*}$ & $\begin{array}{c}\text { "Once every two } \\
\text { years or irregular, } \\
\%^{\prime \prime}\end{array}$ & $\mathrm{P}^{*}$ \\
\hline Age & & & & \\
$\quad<30$ years & 10.2 & $0.319^{* *}$ & 28.5 & $0.806^{* *}$ \\
30-39 years & 12.4 & & 30.5 & \\
40-49 years & 13.2 & & 28.3 & \\
$\geq 50$ years & 14.9 & & 26.9 & \\
Experience as pharmacist & & & \\
$<10$ years & 10.0 & 0.195 & 29.4 & 0.816 \\
$\geq 10$ years & 14.9 & & 28.0 &
\end{tabular}

Do you know about cervical cancer which develops in uterine cervix?

$\begin{array}{lcccc}\text { No } & 5.8 & 0.020 & 17.3 & 0.002 \\ \text { Yes } & 14.7 & & 33.3 & \end{array}$

Do you know about HPV with which most people experience infection?

$\begin{array}{lcccc}\text { No } & 8.0 & 0.119 & 15.0 & <0.0001 \\ \text { Yes } & 14.1 & & 34.9 & \end{array}$

Do you know that persistent infection with HPV can lead to cervical cancer?

$\begin{array}{lcccc}\text { No } & 7.3 & 0.177 & 18.3 & 0.018 \\ \text { Yes } & 13.6 & & 31.8 & \end{array}$

Do you know that HPV can be transmitted by sexual intercourse?

$\begin{array}{lcccc}\text { No } & 3.5 & 0.027 & 19.3 & 0.110 \\ \text { Yes } & 13.8 & & 30.5 & \end{array}$

Do you know about HPV vaccines?

$\begin{array}{lcccc}\text { No } & 4.6 & 0.003 & 18.4 & 0.005 \\ \text { Yes } & 15.4 & & 33.2 & \end{array}$

Do you know about HPV testing?

\begin{tabular}{ccccc} 
No & 12.7 & 0.447 & 29.5 & 0.459 \\
Yes & 7.5 & & 22.5 & \\
\multicolumn{5}{l}{$\begin{array}{l}\text { Do you know about cervical cytology? } \\
\text { No }\end{array}$} \\
Yes & 14.5 & 0.066 & 33.8 & 0.005 \\
\end{tabular}

Do you know differences of the cervical cytology and the HPV testing?

$\begin{array}{lcccc}\text { No } & 8.7 & 0.005 & 23.0 & 0.0004 \\ \text { Yes } & 20.0 & & 41.8 & \end{array}$

Do you know that you can receive cervical cancer tests at a subsidized price by companies or governments?

\begin{tabular}{lcccc} 
No & 4.6 & 0.003 & 15.5 & 0.0002 \\
Yes & 15.5 & & 34.5 & \\
\hline
\end{tabular}

HPV, human papillomavirus; *, Fisher's exact test; **, CochranArmitage trend test.

HPV vaccine and screening is important (Garland et al., 2018). We therefore investigated the statuses of both HPV vaccine and cervical cancer screening, and to our knowledge, this is the first report that investigated the correlations between knowledge and these statuses.

The information source of cervical cancer were greatly different across age groups. Younger pharmacists tended to be informed by school curriculums, while older pharmacists were mainly informed by the internet, the media, and training seminars. Younger pharmacists had more opportunities to learn about cervical cancers in school because the relevance between cervical cancer and HPV became apparent in the 1980s and early 1990s (Lowy et al., 2008), hence contributing to their rich knowledge about cervical cancer and HPV. These results suggested that educating cervical cancer in school is exceptionally effective. For pharmacists aged $\geq 40$ years, edification through the internet, media, and training seminars seemed to be effective.

In Japan, cervical cytology is the standard approach for cervical cancer screening and it is covered by insurance. HPV testing, in contrast, is only covered by insurance when patient is diagnosed with atypical squamous cells of undetermined significance (ASC-US) by cervical cytology. Unlike overseas, HPV testing is not widespread in Japan and only a few individuals have experience undergoing the test. However, in this study, 12.2\% of females received HPV testing once every two years, and $16.6 \%$ received it irregularly. The screening rates of HPV testing in this study seem to be high. Some pharmacies to which the participants belong provides service of HPV testing on self-samples to the customer. Purchasing the service themselves and receiving HPV testing might cause an increase in the screening rates.

Of the 362 female pharmacists, $35.1 \%$ received cervical cytology once every two years. In contrast, some westernized countries have reported screening rates as high as $80 \%$ (OECD, 2013). Only $21.2 \%$ of pharmacists aged $<30$ years received cervical cytology once every two years, despite screening being recommended to begin at age 20 in Japan. This tendency towards lower screening rates among younger pharmacists is consistent with the Comprehensive Survey of Living Conditions of the general population (Japanese MHLW, 2016). Our survey showed that the HPV vaccination rate of pharmacists aged $<30$ years was remarkably high at $29.2 \%$. This result seemed to be caused by the fact that 20-25 year-old females during the investigation period were subjects of the national HPV vaccine program. The HPV vaccination rate was significantly higher only with the knowledge about HPV vaccines and the transmission route of HPV, whereas no differences were observed in other overall knowledge about cervical cancer and HPV. These results indicated that vaccination status is more influenced by whether or not the subjects were part of the HPV vaccine program, rather than the presence or absence of knowledge. Suspending active recommendation for HPV vaccination, rather than the hindrance of information dissemination, hence imposes a greater impact towards vaccination rates. The dissemination of knowledge is obviously important; however, government recommendations and the national HPV vaccine program are more effective for increasing vaccination. The Japan Society of Obstetrics and Genecology considered that HPV vaccination is necessary from a scientific view and has issued a statement strongly urging the government to resume recommendations for the HPV vaccination (Japan Society of Obstetrics and Genecology, 2015). On the other hand, the proportion of pharmacists who underwent cervical cytology and HPV tests (once every two years or irregularly) was significantly higher among those with knowledge about cervical cancer and HPV. This indicated that the spreading of adequate knowledge is effective in promoting cervical cancer screening. In fact, a previous study showed that 
low perceived susceptibility to the disease and the lack of knowledge are the possible barriers of cervical cancer screening (Oshima and Maezawa, 2013).

According to a previous survey by Suzuki et al., (2019) in Japan, in the laypersons' group, females had a significantly higher level of knowledge about cervical cancer and HPV than males; whereas in the medical profession group, there were no differences in level of knowledge between genders. However, in our survey, the proportion of pharmacists with knowledge about cervical cancer and HPV was significantly higher among females than males. This inconsistency seemed to be caused by the differences in job category of the participants and in the method of assessing knowledge. In the survey by Suzuki et al., (2019), the medical profession group included medical school students, nursing school students, other medical students, medical doctors, nurses, public health nurses, midwifes, pharmacists, medical laboratory technicians and other medical professionals. They conducted the survey in 21 locations, including public spaces, classrooms, company offices, university festivals, citizens' open forums and an academic meeting, and assessed the knowledge level of cervical cancer and HPV by correct answer rates for 11 questions. It was stated that one of the limitations of their study was selection bias, in that the participants might have had more interest in health promotion, cervical cancer or HPV. The HPV vaccine is known and described as a "cervical cancer preventive vaccine", and little is known about the prevention of other HPV-related cancers in Japan. The importance of HPV vaccination in boys have attracted global attention, because high-risk HPV can also cause other cancers such as vaginal, vulvar, anal, penile, oropharyngeal, and oral cancers (Lowy et al., 2008). In Australia, the vaccination rate of 15 -year-old boys in 2016 was reported to be $72.9 \%$ (Hall et al., 2019). Therefore, the risk of HPV-related cancers should not be disregarded in males.

This study indicated that the pharmacists' knowledge varied widely depending on their characteristics such as sex, age, and experience as a pharmacist. Ideally, all pharmacists should have a high level of knowledge level regardless of their characteristics. Therefore, the knowledge gap should be filled by adequate resources. Previous studies have reported a positive influence of medical professionals on the acceptability of the HPV vaccination (Gamble et al., 2010; Khan et al., 2016). Pharmacists with high knowledge and a sense of mission are essential in assisting the understanding of cervical cancer and HPV in the general population, and also in promoting HPV vaccination and cervical cancer screening. Our findings advocate the improvement of recommendation behaviors in community pharmacists and the spreading of knowledge for preventing and screening cervical cancer.

In conclusion, our survey revealed that pharmacists' knowledge and attitude towards cervical cancer and HPV significantly varied depending on sex, age, and experience as a pharmacist. This study suggested that the spreading of knowledge about cervical cancer and HPV might be effective in increasing not only the rate of HPV vaccination but also the rate of cervical cancer screening.

\section{Author Contribution Statement}

All authors contributed to this scientific work and approved the final version of the manuscript. AS and designed this study and wrote the manuscript. YN, KF, and $\mathrm{MH}$ were deeply involved in the design of the study. TO performed the data analyses and co-wrote the manuscript. SA supervised the data analyses and co-wrote the manuscript. SY and TG critically revised the manuscript.

\section{Acknowledgements}

The authors thank all of the pharmacists who took the time to participate in the survey to make our study possible.

\section{Ethical approval}

The questionnaire and methodology for this study was approved by the Human Research Ethics committee of the Tsuruha Holdings Inc. (Date 24 April 2019/Ethics approval number: HD2020007). Informed consent was obtained from all individual participants included in the study.

\section{Statement conflict of interest}

The authors have no conflicts of interest to declare.

\section{References}

Bruni L, Diaz M, Barrionuevo-Rosas L et al (2016). Global estimates of human papillomavirus vaccination coverage by region and income level: A Pooled Analysis. Lancet Glob Health, 4, e453-63.

Gakidou E, Nordhagen S, Obermeyer Z, Gakidou E (2008). Coverage of cervical cancer screening in 57 countries: Low Average Levels and Large Inequalities. PLoS Med, 5, e132.

Gamble HL, Klosky JL, Parra GR, Randolph ME (2010). Factors influencing familial decision-making regarding human papillomavirus vaccination. J Pediatr Psychol, 35, 704-15.

Garland SM, Giulian A, Brotherton J, et al (2018). IPVS statement moving towards elimination of cervical cancer as a public health problem. Papillomavirus Res, 5, 87-8.

Gilmour S, Kanda M, Kusumi E, et al (2013). HPV vaccination programme in Japan. Lancet, 382, 768.

GLOBOCAN (2019). Estimated cancer incidence, mortality and prevalence worldwide in 2018 [online]. Available: http://gco. iarc.fr/. Accessed 16 December 2020.

Hanley SJ, Yoshioka E, Ito Y, Kishi R (2015). HPV vaccination crisis in Japan. Lancet, 385, 2571.

Hall MT, Simms KT, Lew JB et al (2019). The projected timeframe until cervical cancer elimination in Australia: a modelling study. Lancet Public Health, 4, e19-27.

Japan Society of Obstetrics and Genecology (2015). Declaration to Demand the Resumption of Recommendations for Human Papillomavirus (HPV) Vaccination for Cervical Cancer Prevention [online]. Available: http://www.jsog. or.jp/modules/en/index.php?content_id=9. Accessed 16 December 2020.

Japanese Ministry of Health, Labour, and Welfare (2016). Comprehensive Survey of Living Conditions in 2016 [online]. Available: https:/www.mhlw.go.jp/english/ database/db-hss/cslc-report2016.html. Accessed 16 December 2020.

Khan TM, Buksh MA, Rehman IU, Saleem A (2016). 
Knowledge, attitudes, and perception towards human papillomavirus among university students in Pakistan. Papillomavirus Res, 2, 122-7.

Liu Y, Di N, Tao X (2020). Knowledge, practice and attitude towards HPV vaccination among college students in Beijing, China. Hum Vaccin Immunother, 16, 116-23.

Lowy DR, Solomon D, Hildesheim A et al (2008). HPV infection and the primary and secondary prevention of cervical cancer. Cancer, 113, 1980-93.

Miyagi E, Motoki Y, Asai-Sato M et al (2014). Web-based recruiting for a survey on knowledge and awareness of cervical cancer prevention among young women living in Kanagawa prefecture, Japan. Int J Gynecol Cancer, 24, 1347-55.

Navalpakam A, Dany M, Hussein IH (2016). Behavioral perceptions of Oakland university female college students towards human papillomavirus vaccination. PLoS One, 11, e155955.

OECD (2013). The OECD Health Care Quality Indicators project: Cancer care, screening survival and mortality for cervical cancer [online]. Available: http://www.oecd.org/ els/health-systems/Health-at-a-Glance-2013.pdf. Accessed 16 December 2020.

Oshima S, Maezawa M (2013). Perception of cervical cancer screening among Japanese university students who have never had a pap smear: a qualitative study. Asian Pac $J$ Cancer Prev, 14, 4313-8.

Oz M, Cetinkaya N, Apaydin A et al (2018). Awareness and knowledge levels of Turkish college students about human papilloma virus infection and vaccine acceptance. J Cancer Educ, 33, 260-8.

Sato N, Fujita K, Kushida K, Chen TF (2020). Exploring the factors influencing the quality of "Health Support Pharmacy" services in Japan: Perspectives of community pharmacists. Res Social Adm Pharm, https://doi.org/10.1016/j. sapharm.2020.02.012.

Simms KT, Hanley SJB, Smith MA, et al (2020). Impact of HPV vaccine hesitancy on cervical cancer in Japan: a modelling study. Lancet Public Health, 5, e223-34.

Sukegawa A, Ohshige K, Arai S, et al (2015). Three-year questionnaire survey on human papillomavirus vaccination targeting new female college students. J Obstet Gynaecol Res, 41, 99-106.

Suzuki Y, Sukegawa A, Nishikawa A et al (2019). Current knowledge of and attitudes toward human papillomavirusrelated disease prevention among Japanese: A large-scale questionnaire study. J Obstet Gynaecol Res, 45, 994-1005.

WHO (2019). The legal and regulatory framework for community pharmacies in the WHO European Region [online]. Available: https://apps.who.int/iris/ bitstream/handle/10665/326394/9789289054249-eng. pdf? sequence $=1 \&$ isAllowed $=y$. Accessed 16 December 2020.

WHO (2020). Human Papillomavirus (HPV) and Cervical Cancer [online]. Available: http://www.who.int/mediacentre/ factsheets/fs380/en/. Accessed 16 December 2020.

\section{(ब) $(\Theta$}

This work is licensed under a Creative Commons AttributionNon Commercial 4.0 International License. 